\title{
Nelson Rodrigues e o melodrama no teatro contemporâneo: a transposição para o palco do folhetim Escravas do amor, da companhia teatral carioca Fodidos Privilegiados
}

Nelson Rodrigues and melodrama in contemporary theater: the transposition to the stage of Escravas do
amor, by the Rio de Janeiro theater company Fodidos Privilegiados

Carolina Montebelo Barcelos

PUC-Rio

\section{Resumo}

Este estudo tem por objetivo examinar o modo pelo qual a companhia teatral carioca Fodidos Privilegiados, inserida no contexto do teatro contemporâneo do trabalho colaborativo, transpôs o folhetim Escravas do amor para o palco, intensificando cenicamente os elementos melodramáticos presentes no texto original. Através de recursos teatrais próprios da estética da companhia - uso de números coreografados, quadro vivo, narração, economia de cenário e de objetos cênicos-, que são utilizados em quase todas as suas peças, a montagem de Escravas do amor é uma adaptação do folhetim de 530 páginas escrito por Nelson Rodrigues sob o pseudônimo de Suzana Flag. Desse modo, procura-se analisar como os Fodidos Privilegiados encenaram características do folhetim, quais sejam, construção em abismo, embuste e ardil, locais relacionados à intriga (choupana, floresta, albergue e castelo) e personagens como o traidor, o justiceiro, a vítima e o bobo, através de elementos melodramáticos como uso da música, mímica facial e corporal, gestos grandes e uso exacerbado da voz. Como aporte teórico no que diz respeito ao melodrama e folhetim, são utilizados estudos de Silvia Oroz, Marlyse Meyer e Jesús Martín-Barbero.

Palavras-chave: teatro contemporâneo; companhia teatral carioca; melodrama; folhetim; Nelson Rodrigues

\section{Abstract}

This study aims at examining the way in which Fodidos Privilegiados, a theatre company from Rio de Janeiro placed into the context of the collaborative work of contemporary theatre, transposed the feuilleton Escravas do amor to stage, scenically intensifying the melodramatic elements present in the original text. By means of the theatrical resources unique to the company's aesthetics - use of choreographed pieces, tableau vivant, narration, economy of scenery and props -, which are used in almost all their plays, the staging of Escravas do amor is an adaptation of the 530 page feuilleton written by Nelson Rodrigues under the pseudonym of Suzana Flag. Thus, this study strives to analyze how Fodidos Privilegiados staged feuilleton characteristics such as abyss construction, deception, ruse, places related to the plot (cottage, forest, lodge and castle) and characters such as the traitor, the avenger, the victim and the fool, through melodramatic elements like use of music, face and body miming, large movements and exaggerated use of voice. The studies carried out by Silvia Oroz, Marlyse Meyer and Jesús Martín-Barbero are used as theoretical underpinning with regard to melodrama and feuilleton. Keywords: contemporary theatre; theatre company from Rio de Janeiro; melodrama, feuilleton; Nelson Rodrigues 
Acaba de me ocorrer uma outra verdade: a grande dor, não só se assoa, como é bumorística. A grande dor, aquela que não tem nenbum consolo terreno, dança mambo. A pessoa pula, chocalha e tem espasmos de mambo.

Nelson Rodrigues

\section{Introdução}

Autor maldito. Flor de obsessão. Imoral. Genial. Obsceno. Revolucionário do teatro. Tarado. Reacionário. Anjo pornográfico. Tais predicados sempre estiveram relacionados ao cronista, contista, romancista e dramaturgo Nelson Rodrigues. Se outrora ele arrancava vaias e aplausos da plateia, críticas ferozes e elogios contundentes, hoje ele está inserido em um rol de autores canônicos brasileiros, destacando-se como um gênio incontestável e não mais como um "autor desagradável" ou pela controvérsia que seus textos causavam. Embora considerasse toda unanimidade burra, Nelson é hoje, paradoxalmente, um autor unânime.

No entanto, não é apenas a figura de Nelson que vem sofrendo um processo de diluição; a leitura de sua obra dramatúrgica também tem se afastado, em diversas montagens, de sua tônica dramática. Como argumenta Victor Hugo Adler Pereira, "É possível sustentar o interesse pelo teatro de Nelson eliminando o clima tenso (e intenso) provocado pela hipérbole e o páthos, marcas características dele, ou ainda, descaracterizando os ingredientes populares do dito mau-gosto?"20 . Desse modo, Adler Pereira analisa tanto as montagens de peças rodrigueanas que operam "um esfriamento do drama original" 1 quanto aquelas em que os elementos que compõem a escrita rodrigueana são intensificados.

Além dessa diluição do drama rodrigueano, podemos observar em muitas montagens um tom demasiadamente solene, realçando um Nelson sério, sem a ironia trágica e o exagero do melodrama, presente em toda a sua obra. Há encenadores que ainda tendem a sacralizar o autor, como se nada mais pudesse ser dito ou mostrado além do que o texto original propõe.

Muitos encenadores também parecem propor uma universalização da obra rodrigueana, privilegiando os aspectos arquetípicos das obras em detrimento do cotidiano, principalmente carioca ${ }^{22}$, e dos elementos cômicos e grotescos.

20 PEREIRA, Victor Hugo Adler. "Dessa vez foi mais leve: intensificação e diluição nas leituras de Nelson Rodrigues", 2012, p. 100.

21 Ibidem, p. 100.

22 Dessa forma, as ações parecem se passar em qualquer lugar e não necessariamente no Rio de Janeiro. Ao se enfatizar cenicamente, por exemplo, os elementos expressionistas identificados nos textos, nas montagens de Antunes Filho de Nelson Rodrigues, o eterno retorno (1981) e de Paraíso zona norte (1989), assim como em Toda nudez será castigada (2006), do Armazém Companhia de Teatro, o espaço carioca em que as peças de Nelson se inserem é, praticamente, apagado nas encenações. 
É curioso que justamente um grupo teatral carioca, Os comediantes, tenha sido vinculado ao conceito de teatro moderno no Brasil, através da montagem de Vestido de noiva, de Nelson Rodrigues, em $1943^{23}$, e nos dias atuais haja uma carência de estudos relativos às montagens contemporâneas de textos rodrigueanos realizadas por companhias. Entretanto, muitas delas vêm montando no Rio de Janeiro, ao longo dos últimos vinte anos, peças do universo rodrigueano.

Dessa forma, esse estudo procura examinar o modo pelo qual a companhia teatral Fodidos Privilegiados, inserida no contexto do teatro contemporâneo do trabalho colaborativo ${ }^{24}$, transpôs 0 folhetim Escravas do amor para o palco, intensificando, cenicamente, os elementos melodramáticos presentes no texto original.

Importante ressaltar que mesmo que o folhetim tenha surgido, em muito, devido ao melodrama, como nos informa Silvia Oroz:

\begin{abstract}
a novela de folhetim não significa, necessariamente, a substituição do melodrama, mas um desvio para novas formas de difusão com conteúdos semelhantes. Os laços entre ambas as formas narrativas são tão estreitos que, hoje em dia, nos países latino-americanos, é usada a palavra 'folhetim' para se referir ao melodrama ${ }^{25}$.
\end{abstract}

\title{
Escravas do amor, dos Fodidos Privilegiados
}

A companhia teatral Fodidos Privilegiados foi fundada pelo diretor Antônio Abujamra em 1991. Em 2000, João Fonseca, após alguns anos de parceria com Abujamra, assumiu sozinho a direção da companhia. A partir disso, as peças passaram a contar com trabalho colaborativo dos atores, isto é, a encenação não era construída através do olhar único do diretor, contando com colaboração dos atores, ensejando uma criação partilhada. Na perspectiva do teatro contemporâneo, no qual atores e diretores usam o texto escrito de forma mais livre, os Fodidos Privilegiados encenaram diversos textos dramatúrgicos e não dramatúrgicos, entre eles, textos de Nelson Rodrigues como a peça A serpente, em 1991; crônicas e o folhetim O bomem proibido, em O que é bom em segredo é melbor em público, em 1996, e, no ano seguinte, a adaptação do romance $O$ casamento. A adaptação do folhetim Escravas

23 A esse respeito, Sábato Magaldi assinala que "O impacto provocado por Vestido de noiva e pelos Comediantes teve reflexo por toda parte" (MAGALDI, 2006, p. 59), estimulando o surgimento de diversos grupos de teatro no país.

24 Tanto a criação coletiva como o trabalho colaborativo concebem o ator como elemento fundamental da criação cênica; enquanto no primeiro os atores participam ativamente da elaboração e composição da peça, no segundo o diretor/encenador unifica e se responsabiliza pela adaptação do texto, ao passo que os atores se desdobram em outras funções (cenário, maquiagem, figurino, trilha sonora), além de proporem ideias para a encenação.

25 OROZ, Silvia. Melodrama: o cinema de lágrimas na América Latina, 1999, p. 23. 
do amor $^{26}$, por seu turno, estreou em 2006 no Centro Cultural Telemar no Rio de Janeiro, reestreou em diversos teatros desde então e faz parte do repertório da companhia junto com $O$ casamento.

Escravas do amor, de Nelson Rodrigues, é um folhetim de quarenta capítulos em 530 páginas na versão em livro. A história se passa nos anos 40: no dia de seu noivado, Malu, que ainda não beijou o seu noivo Ricardo, o vê matar-se. Na mesma casa, o pai é ameaçado pela amante e a mãe sofre pela morte do futuro genro mais que a filha. A principal história se desenvolve a partir desses fatos que compõem os dois primeiros capítulos e diz respeito a acontecimentos estranhos e misteriosos. As outras histórias, que vão se desenrolando paralelamente, se mostram, de alguma forma, ligadas a esses acontecimentos, embora o autor se valha de pistas falsas e apresente uma intriga que não revela claramente as intenções e motivações dos personagens.

Com uma sucessão rápida de acontecimentos e uma diversidade de personagens, como os heróis/heroínas e os vilões, o desconhecido ardiloso, as tias solteironas, o homem disforme, as ações de Escravas do amor são pontuadas por pistas falsas, fait divers ${ }^{27}$, situações banais que levam personagens a ações extremas, clichês, reviravoltas, revelações surpreendentes, até o desfecho final, em que volta a reinar a harmonia em prol de um final feliz. Essa estrutura narrativa corresponde à observação de Marlyse Meyer sobre o folhetim rocambolesco:

Internamente o texto apresenta os mais variados processos narrativos, que emprestam todos os modelos para compor uma vertiginosa construção em abismo estruturada em embuste e ardil como forma de articulação do enredo: embuste de verdade, embuste de mentira, vítimas de verdade, vítimas de mentira... ${ }^{28 .}$

O termo rocambolesco é cunhado a partir da série As aventuras de Rocambole, de Ponson du Terrail. Marlyse Meyer explica o termo como "sinônimo de delirante aventura, enrolada como o bolo ao qual deu o nome"29 e acrescenta:

Verdadeiro turbilhão, espiral aventureira a evocar [...] o rocambolesco foi uma nova receita dentro do grande gênero folhetinesco, inventado pelo novo mestre-cuca Ponson Du Terrail. Um gênero que, ao contrário do que se espera do folhetim-lugarcomum, não visava emocionar, nem pretendia tranquilidade... ${ }^{30}$.

26 Um ano após o sucesso de Vestido de noiva, Nelson Rodrigues foi contratado pelos Diários Associados para escrever um folhetim. Para não ser identificado com suas peças e crônicas, adotou o pseudônimo de Suzana Flag. O primeiro folhetim, Meu destino é pecar, fez tanto sucesso que foi editado em livro após o fim de seu último capítulo publicado no jornal. Tal êxito levou Nelson a escrever, no mesmo ano de 1944, seu segundo folhetim Escravas do amor. Outros folhetins, então, se seguiram: Minba vida (1947), Núpcias de fogo (1949), A mulber que amou demais (1951, sob o pseudônimo de Mirna), O bomem proibido (1959), A mentira (1953) e Asfalto selvagem (1959/60, dessa vez assinado com o nome próprio do escritor).

27 Trata-se de exagero e repetição dos temas, forte expressão de sentimentos, dramatização dos fatos, arrebatamento, hipérbole e metáfora, suspense, pessoas transformadas em personagens.

28 MEYER, Marlyse. Folhetim: uma história, 1996, p. 159.

29 Ibidem, p. 157.

30 Ibidem, p. 157. 
Ainda segundo Meyer, no fazer rocambolesco, "o texto é definido externamente pela forma como é apresentado: o fragmento cotidiano do jornal, que vai por sua vez constituindo fascículos que levam ao todo do volume" ${ }^{" 1}$. Assim, foi publicado Escravas do amor, em O Jornal, em 1944, antes de ser lançado em livro.

O folhetim foi encenado com ritmo ágil pelos Fodidos Privilegiados, através de marcas, direção e movimento dos atores. A montagem não é uma transposição literal do texto rodrigueano no palco, mas uma releitura do folhetim por meio de uma linguagem própria da companhia, sem perder de vista aquele aspecto que talvez seja o mais forte do texto: o elemento melodramático ${ }^{32}$.

Cada cena da montagem do folhetim é anunciada por um ator como capítulo, assim como ocorre no texto original. Por exemplo, dois dos atores anunciam, após a apresentação do espetáculo e da companhia, algo que ocorre em várias peças dos Fodidos Privilegiados, o primeiro capítulo, "Fim do meu sonho de amor".

No entanto, os títulos e ordens dos capítulos da peça não necessariamente correspondem aos do folhetim. Apesar dos três primeiros capítulos serem os mesmos nos dois textos, o quarto capítulo da peça corresponde ao vigésimo sétimo do folhetim, por exemplo, assim como dois títulos de capítulos da peça não se encontram no texto original. Há, também, diversos acontecimentos em capítulos diferentes do folhetim condensados em um mesmo capítulo na peça. Após a encenação do capítulo 15, por exemplo, quando parece que a peça não tem fim, já que se trata de um texto de quarenta capítulos, o ator anuncia o resumo dos próximos capítulos, até a apresentação do capítulo final, que condensa os acontecimentos dos últimos cinco capítulos do folhetim, embora com título do capítulo 36.

$\mathrm{Na}$ montagem dos Fodidos Privilegiados, a maior parte das cenas/capítulos é iniciada com a repetição do final da cena anterior, tal como nas novelas. Um exemplo disso é a cena em que Lígia conta à filha que o genro a beijou, cena que encerra o primeiro capítulo e inicia o segundo com o acréscimo de dois outros grupos de três atores fazendo o duplo de Ricardo morto, Lígia e Malu.

Nelson, por vezes, também utiliza recurso semelhante, embora, em seu texto, o capítulo seguinte não seja a exata repetição do anterior, mas a retomada da situação: o capítulo 2 se encerra com Malu dizendo ao Dr. Meira: “- Mas uma coisa eu digo: nunca serei fiel a homem nenhum. Posso namorar, ficar noiva, me casar, mas não serei fiel, garanto!”33 . O terceiro capítulo abre "D. Lígia ouviu a filha dizer aquilo: 'Nunca serei fiel a homem nenhum!', mas não fez comentário, não se perturbou...”’34. Assim como ocorre no texto rodrigueano, a maioria dos capítulos da peça encerra com uma situação para

31 Ibidem, p. 159.

32 Nesse sentido, é importante notar que a obra rodrigueana não se insere em um gênero ou estilo literário ou teatral específico. Embora Nelson tenha iniciado seu exercício da escrita no jornalismo, suas primeiras notícias de reportagens policiais, assim como suas crônicas esportivas, crônicas de Pouco amor não é amor e de A vida como ela é, carregam nas tintas da dramaticidade, do melodrama, do trágico e do expressionismo e, da mesma forma, as peças, os folhetins e o romance. Pode-se afirmar, portanto, que a obra rodrigueana é uma interface de diversos gêneros e estilos relidos pelo escritor.

33 RODRIGUES, Nelson (Suzana Flag). Escravas do amor, 2001, p. 35.

34 Ibidem. p. 36. 
gerar expectativa, "um gancho falso", como no segundo capítulo, quando Malu vai revelar o nome da mulher com quem o noivo a traiu, mas, apesar de o terceiro capítulo iniciar com o final do anterior, o nome da mulher não é revelado.

Ao trazer Escravas do amor para o palco, os Fodidos Privilegiados se valem de marcas e elementos cênicos próprios da estética da companhia, tais como narração, quadros vivos, economia de cenário, poucos objetos cênicos utilizados simbolicamente ${ }^{35}$, números coreografados que unem algumas cenas, para conferir um ritmo ágil à peça. Enquanto o tradicional palco do melodrama contava com cenários diversificados e engenhosos, a companhia optou pela composição apenas de cadeiras no palco, onde os personagens observam a ação, esperam para "entrar em cena" ou se levantam para narrar as ações.

No melodrama tradicional, havia sempre um conjunto de locais diretamente relacionados à intriga: a choupana, a floresta, o albergue e o castelo. Nelson também localiza as ações de Escravas do amor nesses espaços, pois o castelo, "lugar do poder e da riqueza"36, aparece no folhetim como a casa da família rica de Malu; a floresta, "um lugar não delimitado, de perigo e agressões" ${ }^{77}$, é onde Malu é levada por Glorinha que, refugiada na "caverna”, observa a chegada da onça que deveria devorar Malu, mas acaba atacando Bob.

Ao invés de se valer de toda uma maquinaria cenográfica para a locação desses ambientes, os Fodidos Privilegiados preferem o espaço cênico quase nu, com cenário de Nello Marrese. No fundo do palco, a imagem de um caracol de rosas vermelhas parece ilustrar a trama rocambolesca que parece não ter fim e o barbante entrelaçado sugere as diversas histórias que se cruzam, se entrelaçam. Dessa forma, há essencialmente cadeiras em cena, mudadas de lugar dependendo da necessidade de composição da cena e onde os atores se revezam para comporem as diversas cenas, às vezes, abandonando seu próprio personagem para fazer o duplo de um outro.

As várias narrações são feitas pelos personagens em terceira pessoa, um dos elementos brechtianos utilizados pela companhia, enquanto executam a ação narrada. Algumas vezes um personagem narra a ação do outro, por outras, é o próprio personagem que narra sua ação. Um exemplo é a cena em que Malu está na piscina e que é narrada por dois atores.

Como assinala Thomasseau, os atores exerceram papel fundamental para o sucesso do melodrama e contavam com a mímica facial e corporal, gestos grandes e uso exacerbado da voz para comporem seus personagens ${ }^{38}$. O uso que os atores dos Fodidos Privilegiados fazem do corpo e da voz sublinha esse tipo de atuação melodramática e eles, muitas vezes, congelam a ação em um quadro vivo, sugerindo uma imagem com intuito claro de mostrar personagens estereotipados. Há, por exemplo, uma cena em que

35 Como a corda segurada por cada ponta pelas primas de Malu, remetendo à piscina onde ela se encontra antes da primeira chegada do noivo.

36 THOMASSEAU, Jean-Marie. O melodrama, 2012, p. 129.

37 Ibidem, p. 129.

38 Ibidem, p. 132. 
Ricardo é encontrado morto - ele havia se suicidado - e dez personagens em quadro vivo ${ }^{39}$ o cercam, com expressões faciais e gestos estereotipados de espanto e desespero.

Embora Thomasseau argumente que "por seu gosto pelas situações, o melodrama foi uma das primeiras formas teatrais a se desligar deliberadamente da escrita tradicional do teatro, preferindo uma linguagem puramente cênica que era, inicialmente, a da ação e das imagens" ${ }^{\text {”40 }}$, Nelson consegue, através de sua escrita, de uma linguagem excessiva e rica em detalhes e adjetivos, criar imagens que mostram os pensamentos, as ações e os gestos dos personagens. Essa linguagem excessiva, entretanto, era algo incomum no melodrama tradicional, que privilegiava a economia verbal. Conforme assinala Silvia Oroz, "a partir de suas origens musicais, o melodrama propõe-se à simplificação formal e ao 'apelo direto aos sentimentos e sua compreensão"'¹:

Mag deu o salto. Malu teve a noção do movimento da fera; desesperou-se, correu. A fera passou; uma pata raspou pelo ombro da moça, levou um pedaço do vestido, rasgou-lhe o ombro. Ela não sentiu dor nenhuma, nem teve tempo de sentir. Com a forças duplicadas pelo terror, correu mais, sem direção, alucinada. "vou enlouquecer", era a sua sensação, a sua certeza. Seus nervos não resistiram, parecia atingir o máximo de tensão. E desejava mesmo a loucura, ficar louca, perder a noção da dor e do perigo. Mas não estava livre. A fera voltava. Sempre correndo com todas as forças, Malu foi olhar para trás - tropeçou e caiu. Numa fração de segundo, com todos os nervos contraídos, esperou sentir nas costas o peso de Mag, as suas garras e os seus dentes. Era a morte, e, pior do que isso, a deformação: naquele segundo, ou naquele décimo de segundo, passou pelo seu pensamento uma porção de coisas; viu-se a si mesma mutilada, estraçalhada, arrastada, no chão ${ }^{42}$.

Essa linguagem excessiva, carregada de adjetivações, do folhetim rodrigueano, é sublinhada na encenação por expressão, gesto e movimento corporal dos atores, quase como uma mímica, um dos elementos constitutivos do melodrama teatral tradicional. Toda cena citada acima é mostrada na peça através da reação da atriz do que seria o ataque da onça. Tal como na mímica, a atriz usa o movimento, o gesto, a expressão facial para trazer a imagem de seu horror com a onça, sem a necessidade de usar. Como assinala Martín-Barbero, o corpo, seus gestos e expressões têm, no espetáculo melodramático, tanta ou mais importância que a fala ${ }^{43}$.

Barbero também assinala as quatro personagens básicas que compõem o melodrama: o traidor, o justiceiro, a vítima e o bobo ${ }^{44}$. Na cena descrita acima, se encontram três desses personagens: Glorinha

39 Quadro vivo, do francês tableau vivant, é uma cena congelada em que os atores, ficam imóveis, mas sugerindo uma expressividade, como em uma estátua ou pintura.

40 Ibidem, p. 128.

41 OROZ, Silvia. Melodrama: o cinema de lágrimas na América Latina, 1999, p. 17.

42 RODRIGUES, Nelson (Suzana Flag). Escravas do amor, 2001, p. 134.

43 MARTIN-BARBERO, Jesús. Dos meios às mediações: comunicação, cultura e hegemonia, 2006, p. 162.

44 Ibidem, p. 162. 
é a traidora ${ }^{45}$ (que levou Malu à floresta onde seria morta), Malu é a vítima, e, Bob, o justiceiro, que se entrega à onça para salvar Malu, por quem é apaixonado. Os quatro sentimentos básicos presentes no melodrama; medo, entusiasmo, dor e riso; se expressam, segundo Barbero, através das ações desses quatro personagens. Esses elementos, além de estarem presentes no folhetim de Nelson, são sublinhados pela encenação dos Fodidos Privilegiados através do trabalho dos atores, da iluminação e da trilha sonora. Temos, ainda na cena descrita acima, por exemplo, a reunião desses elementos, com o misterioso Prof. Jacob, seu plano de matar Malu com a onça, seu entusiasmo em vê-la sozinha com a fera, enquanto uma assustada Glorinha ouve a tudo e Malu expressa, através de gestos, expressões e movimentos, seu medo e sua dor.

A música, outro elemento constitutivo do melodrama, como assinala Thomasseau, "é ao mesmo tempo expressiva e descritiva. Sua função é, inicialmente, emocional: ela substitui o diálogo na pantomima, prepara e sustenta os efeitos dramáticos e patéticos, acompanha a entrada e a saída dos personagens”“46. Dessa forma, a trilha sonora de João Fonseca e Rafaela Amado dá esse tom do melodrama, pois as ações são reforçadas ou costuradas pelos atores, apresentando-se diretamente para a plateia, ao som de tangos e boleros. As músicas foram escolhidas de modo que a letra antecipe ou ilustre, de alguma forma, o personagem. Ao surgir pela primeira vez, Glorinha, amante do pai de Malu, se apresenta sob a voz de Dalva de Oliveira cantando Folha morta ${ }^{47}$. As cenas de beijos também se valem de músicas que reforçam as ações, como o primeiro beijo que o noivo de Malu dá na sogra Lígia ao som de Frenesi e o beijo da mesma Lígia em Carlos, ilustrado por Besame mucho. Cada capítulo é encerrado com uma música comum às radionovelas, assim como a repetição da cena anterior no início de cada capítulo também nos remete às novelas.

Assim como a música, o balé:

outra convenção do melodrama, entrava também nesta combinatória mímicalinguagem-música-quadro [...] Ele intervinha, efetivamente, tanto no início do primeiro ato, na descrição da felicidade que precedia a chegada do vilão, como no meio da peça [...]. Algumas vezes ele tinha também lugar nas cenas finais, durante os episódios de reconhecimento ${ }^{48}$.

Apesar de não propriamente mostrar um balé em cena, há momentos de números coreografados por Ana Beviláqua, servindo ao propósito assinalado acima por Thomasseau. Um número coreografado,

45 Importante observar que os personagens rodrigueanos em Escravas do amor não apresentam em sua totalidade as identidades estanques dos personagens melodramáticos. Glorinha, por exemplo, só se mostra como traidora nessa cena; por muitas vezes ela pode ser vista como vítima de seu relacionamento com Dr. Carlos. O grande traidor, vilão, é revelado somente no final do folhetim e da peça: Prof. Jacob.

46 THOMASSEAU, Jean-Marie. O melodrama, 2012, p. 131.

47 O início da música já dá o tom do personagem: "Sei que falam de mim, Sei que zombam de mim, Oh, Deus, Como sou infeliz". Essa seria a imagem que a mulher, no papel de amante, teria para a sociedade da década de 40.

48 Ibidem, p. 131-132. 
um andar e um movimento lento ao som de tango composto pelos personagens femininos, abre a peça após a chamada do primeiro capítulo.

O fechamento mais tradicional do melodrama, final feliz para os bons e castigo, principalmente morte, para os maus, também pode ser visto em Escravas do amor. Ao reunir em um único capítulo final os cinco últimos capítulos do folhetim, percebe-se, mais claramente, a utilização do recurso do coup de théatre através das revelações após várias pistas falsas, além das reviravoltas súbitas. A esse respeito, diz Marlyse Meyer sobre o rocambolesco: "Vemos aí o germe do processo folhetinesco e novelo-televisivo, ou seja, a adição de infinitos enredos paralelos, mas imbricados por um elemento que pertence ao enredo principal, que só se desvendam para serem costurados no epílogo" ${ }^{\text {99. }}$. Dessa forma, na última cena da peça, descobrimos a vingança planejada por Jacob (havia hipnotizado vários personagens) contra Dr. Carlos, motivada pelo suicídio da filha por amor a Carlos, homem casado; a morte de Jacob; a revelação da troca dos filhos (Malu e Claudio) de Lígia e Laura na maternidade, que justifica o amor que Lígia sentia em relação a Claudio (não mais passional, agora materno); Bob se revela um milionário excêntrico, faz plástica para reverter a deformidade causada pelo ataque da onça e fica bonito para se casar com Malu.

\section{Considerações finais}

Ao contrário de muitas montagens de Nelson que provocam um "esfriamento do drama" rodrigueano, parafraseando aqui a expressão utilizada por Victor Hugo Adler Pereira ${ }^{50}$, na montagem dos Fodidos Privilegiados de Escravas do amor, a hipérbole, o páthos, o grotesco e o cômico, assim como os elementos melodramáticos, são revisitados e relidos de acordo com as marcas e elementos cênicos característicos dos trabalhos da companhia.

O sentimento melodramático - fait divers, reviravoltas súbitas, coup de théatre, exageros e hipérbole - perpassa toda a obra rodrigueana: as crônicas de A vida como ela é e de Pouco amor não é amor, as tragédias cariocas, as peças míticas e psicológicas, além das crônicas esportivas. No entanto, Nelson não escrevia melodrama, mas fazia uma paródia dele.

Não só Nelson Rodrigues parodiou o melodrama em seus textos, como também os Fodidos Privilegiados parodiaram o melodrama rodrigueano na montagem de Escravas do amor. Ao examinar o conceito de paródia no teatro, Patrice Pavis assinala que:

A paródia tende a tornar-se um gênero autônomo e uma técnica para revelar o
procedimento artístico. No teatro, ela se traduzirá num resgate da teatralidade e
num rompimento da ilusão através de uma insistência grande demais nas marcas do
jogo teatral (exagero da declamação, do pathos, do trágico, dos efeitos cênicos) ${ }^{51}$.

49 MEYER, Marlyse. Folhetim: uma história, 1996, p. 161.

50 PEREIRA, Victor Hugo Adler. "Dessa vez foi mais leve: intensificação e diluição nas leituras de Nelson Rodrigues". In: Nelson Rodrigues, o freudismo e o carnaval nos teatros modernos, 2012.

51 PAVIS, Patrice. Dicionário de teatro, 1999, p. 278. 
Ao realizar a paródia, a companhia se valeu de seu repertório de elementos e marcas cênicas para destacar e ressaltar os exageros e as hipérboles do texto rodrigueano, realizando um exercício intra e intertextual e homenageando o dramaturgo e escritor Nelson Rodrigues. A esse respeito, diz Pavis:

\begin{abstract}
O discurso parodiante nunca deve permitir que se esqueça o alvo parodiado, sob pena de perder a força crítica. Ele cita o discurso original deformando-o; apela constantemente para o esforço de reconstituição do leitor ou do espectador. Sendo ao mesmo tempo citação e criação original, mantém com o pré-texto estreitas relações intertextuais. Mais que imitação grosseira ou travestimento, a paródia exibe o objeto parodiado e, à sua maneira, presta-lhe homenagem" ${ }^{\text {"2 }}$.
\end{abstract}

Além do intertexto mais óbvio que é a adaptação do folhetim, os Fodidos Privilegiados também parecem ter utilizado alguns elementos da escrita dramatúrgica rodrigueana, como as falas curtas e interrompidas, as elipses e o diálogo coloquial que vemos nas tragédias cariocas. Ademais, apesar do folhetim ser rico em diálogos, nos quais esses elementos estão presentes, as narrações são bem longas, enquanto as narrações na montagem seguem o estilo de fala dos personagens. Também a utilização de cadeiras para comporem o cenário pode nos remeter às tragédias cariocas, nas quais, de acordo com as próprias rubricas do texto, as cadeiras alinhadas lado-a-lado, representam o taxi invisível que o personagem Bibelô pega com Aurora rumo à Copacabana, em Os sete gatinhos, e que o personagem Tuninho pega para a casa de Pimentel em A falecida. Nas tragédias cariocas, assim como na montagem dos Fodidos Privilegiados, a economia de cenários e de objetos de cena privilegia o trabalho do ator e da direção, pois a imagem descrita pelo autor no folhetim e detalhada nas rubricas das peças é sugestionada pelo uso do espaço e pela atuação e movimento dos atores.

Embora a encenação dos Fodidos Privilegiados privilegie os aspectos cômicos e grotescos do texto rodrigueano, o trágico, tão essencial e presente na obra rodrigueana, não se mostra elemento preponderante no folhetim Escravas do amor. Nesse sentido, o texto de Nelson se aproxima da definição elaborada por Thomasseau sobre o melodrama, "[...] um gênero teatral que privilegia primeiramente a emoção e a sensação. Sua principal preocupação é fazer variarem estas emoções com a alternância e o contraste de cenas calmas ou movimentadas, alegres ou patéticas" ${ }^{\prime 3}$. Ainda que o folhetim traga temas do universo trágico rodrigueano, tais como incesto, o autor não carrega, aqui, nas tintas da dramaticidade, como fez em crônicas e em toda a sua obra teatral.

O teórico do teatro Jean-Pierre Ryngaert assinala que na cena contemporânea "tudo é representável" ${ }^{\text {, }}$, uma vez que todos os textos seriam dotados de teatralidade sendo, portanto, passíveis de interpretação cênica. No entanto, essa cena contemporânea, tal como exemplificada pela montagem de Escravas do amor pela companhia Fodidos Privilegiados, não está preocupada em explicar o texto

52 Ibidem, p. 278.

53 THOMASSEAU, Jean-Marie. O melodrama, 2012, p. 139.

54 RYNGAERT, Jean-Pierre. Ler o teatro contemporâneo, 1998, p. 31. 
ou servir como ilustração dele, mas mostrar a leitura e a interpretação de uma encenação a partir desse texto que não é somente o texto escrito mas, trata-se, normalmente, de uma variedade de textos que formam um mosaico ou um caleidoscópio desenhado através do olhar unificador do diretor da peça e da contribuição cênica dos diversos atores.

\section{Referências}

MAGALDI, Sábato. Moderna dramaturgia brasileira. São Paulo: Perspectiva, 2006.

MARTIN-BARBERO, Jesús. Dos meios às mediações: comunicação, cultura e hegemonia. Rio de Janeiro: Editora UFRJ, 2006.

PAVIS, Patrice. Dicionário de teatro. São Paulo: Perspectiva, 1999.

MEYER, Marlyse. Folhetim: uma história. São Paulo: Companhia das Letras, 1996.

OROZ, Silvia. Melodrama: o cinema de lágrimas na América Latina. Rio de Janeiro: Funarte, 1999.

PEREIRA, Victor Hugo Adler. "Dessa vez foi mais leve: intensificação e diluição nas leituras de Nelson Rodrigues". In: ___ . Nelson Rodrigues, o freudismo e o carnaval nos teatros modernos. Rio de Janeiro: 7Letras, 2012. p. 99-115.

RODRIGUES, Nelson (Suzana Flag). Escravas do amor. São Paulo: Companhia das Letras, 2001.

RYNGAERT, Jean-Pierre. Ler o teatro contemporâneo. São Paulo: Martins Fontes, 1998.

THOMASSEAU, Jean-Marie. O melodrama. São Paulo: Perspectiva, 2012.

\section{Peça de teatro}

FONSECA, João (dir). Escravas do amor. Peça teatral. Teatro Carlos Gomes, Rio de Janeiro, agosto de 2012. (DVD).

Submissão: $31 / 03 / 2020$

Aceite: $10 / 07 / 2020$

https://doi.org/10.5007/2176-8552.2018n26p15 